\title{
Simple and Robust Fabrication and Characterization of Conductive Carbonized Nanofibers Loaded with Gold Nanoparticles for Bone Tissue Engineering Applications
}

\author{
Houra Nekounam, ${ }^{\mathrm{a}, \mathrm{b}}$, Zahra Allahyari, ${ }^{\mathrm{c}, \mathrm{d}}$,Shayan Gholizadeh $^{\mathrm{c}, \mathrm{d}}$, Esmaeil Mirzaei ${ }^{\mathrm{e}}$, \\ Mohammad Ali Shokrgozar ${ }^{\text {b* }}$, Reza Faridi-Majidi ${ }^{\text {** }}$ \\ a Department of Medical Nanotechnology, School of Advanced Technologies in Medicine, Tehran \\ University of Medical Sciences, Tehran, Iran \\ ${ }^{b}$ National Cell Bank of Iran, Pasteur Institute of Iran, Tehran, Iran \\ c Department of Microsystems Engineering, Rochester Institute of Technology, Rochester, NY, \\ USA \\ ${ }^{d}$ Department of Biomedical Engineering, Rochester Institute of Technology, Rochester, NY, USA \\ e Department of Medical Nanotechnology, Shiraz University of Medical Sciences, Shiraz, Iran
}

*Corresponding authors: Reza Faridi-Majidi, Ph.D

Email: refaridi@sina.tums.ac.ir

Phone: +982143052000

Mohammad Ali Shokrgozar, Ph.D

Email: mashokrgozar@pasteur.ac.ir

Phone: +982166492595 


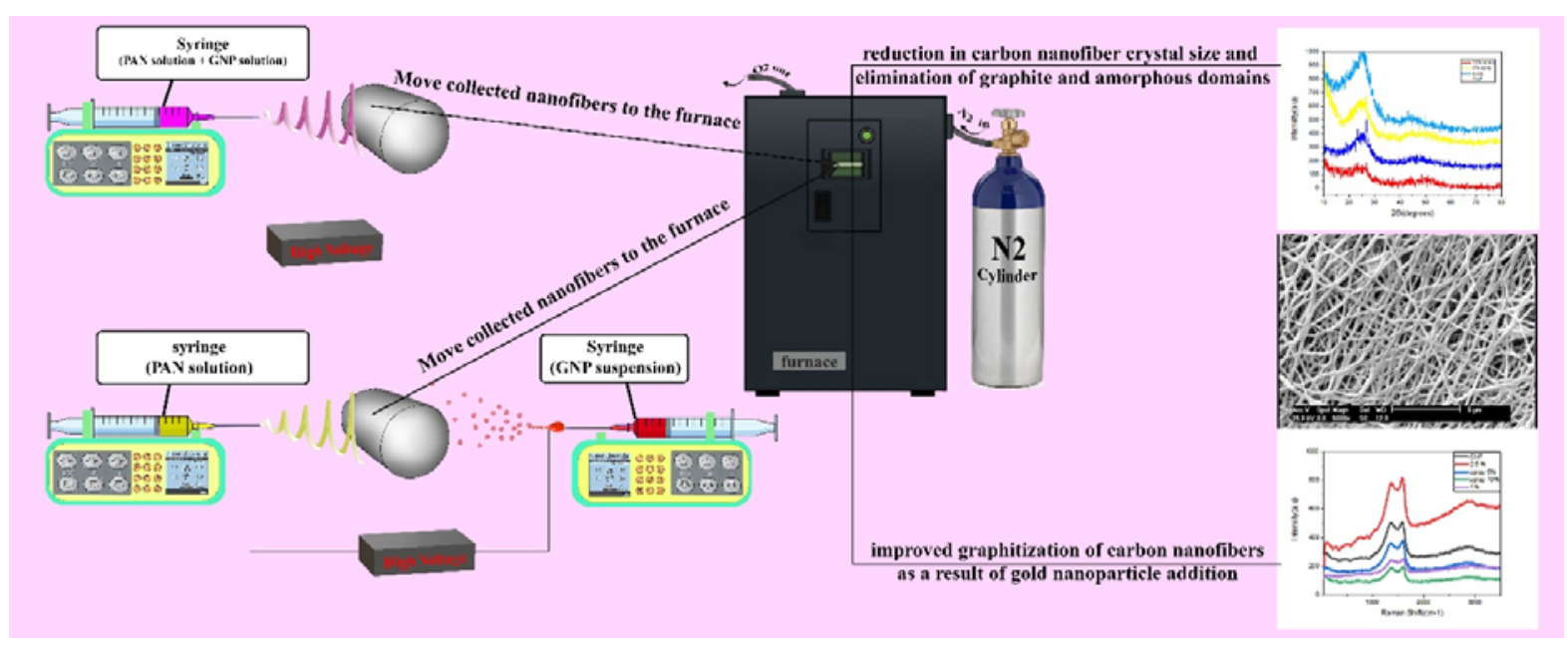

\section{Abstract}

Bone tissue engineering is a new and applicable emerging approach to repair the bone defects. Electrical conductive scaffolds through a physiologically relevant physical signaling, electrical stimulation, has shown a highly promise in this approach. In this paper, we fabricated carbon nanofiber/gold nanoparticle (CNF/GNP) conductive scaffolds using two distinct methods; blending electrospinning in which GNP were blended with electrospinning solution, and electrospinning/electrospraying in which GNP was electrosprayed simultaneously with electrospinning. The obtained electrospun mats underwent stabilization/carbonization process. The scaffolds were characterized by SEM, XRD, FT-IR and Raman spectroscopy. SEM characterizations showed improved morphology and a slight decrease in the diameter of the spinned and sprayed nanofibers (from $178.66 \pm 38.40 \mathrm{~nm}$ to $157.94 \pm 24.14 \mathrm{~nm}$ and $120.81 \pm$ $13.77 \mathrm{~nm}$, respectively), while XRD analysis confirmed the crystal structure of the nanofibers. Raman spectroscopy revealed enhancement in the graphitization of the structure, and the electrical conductivity of the structure improved by up to $29.2 \%$ and $81 \%$ in electrospraying and blending electrospinning modes, respectively. Indirect MTT and LDH toxicity assays directly were performed to assess MG63 cell toxicity, but no significant toxicity was observed and the scaffolds did not adversely affect cell proliferation. It can be concluded this structure have potential for bone tissue engineering applications.

Key Words: Carbon nanofiber, Gold Nanoparticles, Electrospraying, Electrospinning, Cell toxicity, Cell Proliferation 


\section{Introduction}

Bone tissue engineering has emerged in recent years as a potential approach to overcome the difficulties in healing, regeneration and functional restoration of bone defects following damages caused by trauma or as a result of osteoporosis amongst other relevant causes. ${ }^{1-3}$ This approach is usually accompanied by the combination of a synthetic, natural or hybrid 2D or 3D scaffolds, cells, and a physiologically relevant chemical or physical signaling. ${ }^{4-12}$

Despite numerous studies focusing on preparation of bone tissue engineering scaffolds and comprehensive investigations of different scaffold component combinations, there is still muchneeded improvements necessary for integrating bone tissue engineering scaffolds for in-vivo studies with potential significantly superior clinical outcomes. ${ }^{13}$ Such shortcomings are particularly evident in studies with a major or minor focus on electrical stimulation of bone cells or tissue prior or after implantation. ${ }^{14,15}$

These studies require tailored, engineered and repeatable electrical properties of the scaffolds, while also ensuring high biocompatibility, proper cell attachment, adequate mechanical integrity and tissue integration in addition to the golden missing chain between these properties, which is ensuring reproducibility with low fabrication costs. ${ }^{16-18}$ The latter property is still highly sought despite the development of numerous platforms with significant and promising results. ${ }^{16,19}$

Over the different stages of bone tissue engineering scaffold development, electrospinning have been constantly considered as a suitable fabrication method due to the its perceived multifaceted ability to make nano- and micro-fibrous structures from a variety of polymer solutions with tunable fiber characteristics which have been shown to have a dominant effect on bone cell behavior and tissue integration. ${ }^{20-24}$ Nanofibrous and microfibrous scaffolds have long been used for tissue engineering applications due to their inherent compatibility with native extracellular matrix, their high fabrication yield and overall low fabrication costs. ${ }^{9}$ Electrospinning of conductive polymers have been previously addressed and explored. Common examples of conductive polymers include polypyrrole (PPy), polythiophene and, polyaniline ( PANi), with diverse application ranging from biomedical engineering to corrosion protection. ${ }^{25-28}$ Amongst the conductive polymer candidates for electrospun scaffolds, PPy and PANi has been shown to have 
in vitro and in vivo biocompatibility to various degrees depending on the fabrication parameters and intended cells or tissues, especially yielding successful fabrication and biological results when electrospun in blended format. ${ }^{29-33}$ However, elucidating proper biological response from a composition involving electrospun conductive polymers is challenging despite providing the necessary electrical conductivity, which has led to a noticeable downfall in their application in this field and the biocompatibility of these structures and their precursors is challenging. ${ }^{34}$

Structural and surface modification of electrospun scaffolds have relatively been limited to biological molecule coating, inducing changes in surface roughness and addition of a natural component in the scaffold structure. ${ }^{35,36}$ Despite the improvements obtained through these methods, they add challenges and difficulties to the process, especially in terms of fabrication and reproducibility. ${ }^{37}$

Other potential methods for obtaining electrically conductive scaffolds which have been recently more investigated include addition of conductive nanoparticle components and using standard and reproducible techniques such as furnace-enabled carbonization. ${ }^{38-40}$ Both embedding metallic nanoparticles and carbonization can be considered of high interest for bone tissue engineering, since they are tools for structural and surface modification such as decreasing the contact angle, they also contribute to increasing the electrical activity of the prepared scaffold products and gold nanoparticles (AuNPs) specifically can also be used to induce angiogenesis and differentiation to bone lineage. ${ }^{41-43}$ AuNPs are promising materials for bone tissue engineering due to their easy preparation, tunable chemical and electrical properties, antiinflammatory properties, and their successful implementation as osteogenic materials for bone tissue regeneration. In addition to their potential as electrically conductive components of scaffolds, it has been shown that they can be used to module osteoblast cell behavior (including differentiation) and to modify pathways responsible for osteoclast formation, indicating that AuNPs are versatile materials for bone tissue engineering applications. ${ }^{44,45}$

Among candidates to be used for bone tissue engineering scaffolds, carbon nanofibers (CNFs) have been shown to be exceptional materials for bone tissue engineering in terms of mechanical properties, tailored surface energy, biologically-relevant nanoscale topography, spatiallycontrollable bone cell adhesion and bone mineral deposition and biocompatibility. It was 
demonstrated that CNFs-based bone replacements induce better tissue integration and result in better patient outcomes as compared to traditional commercially available options. ${ }^{46,47}$ Additionally, CNFs possess high electrical conductivity which significantly elevate their potential for conductive scaffold applications. ${ }^{46}$

In the present work, Polyacrylonitrile (PAN) polymer solutions were integrated into conductive nanofibrous scaffolds using electrospinning, followed by carbonization in a tube furnace. Gold nanoparticles were embedded either as a blend in PAN solution or they were co-electrospun with the PAN solution, hence providing flexibility in the fabrication process. In situ attachment method was used to fabricate gold nanoparticles on the surface of nanofibers in previous similar works, in which they first synthesized carbon nanofibers and then synthesized gold nanoparticles by adding precursor using different reduction beads or they used the covalent reaction between activated carbon nanofibers and pre-made gold nanoparticles. ${ }^{48,49}$ However, these methods entail certain deficiencies such as complex process, unreliable fabrication and cytotoxicity which create barriers for their in vitro and in vivo applications. ${ }^{50}$ All of the structures that have been developed are mostly based on the role of the sensor and the electrochemical applications with minimal focus on preparing scaffolds with desired biological response and physiologicallyrelevant electrical cues.

In order to circumvent these issues, a need for simple and cost-effective approaches with minimal potential cytotoxic components is sensed in the literature. Providing electrical conductivity is an integral component of such solution, as it provides a positive physical cue for cell behavior if implemented using safe and simple approaches. ${ }^{51,52}$

As it can be observed in the literature, electrical cues are useful in improving the proliferation and differentiation of various tissues including the nerve, heart, bone and skin. Additionally, precious studies have confirmed the positive effect of gold nanoparticles on bone tissue regeneration. All steps were designed for maximal reproducibility and minimal necessary equipment and efforts. In the first method, gold nanoparticles were added to the prepared polymer solution and then the electrospinning process was performed (blending electrospinning method). In the second method, we used side by side electrospinning systems (with polymer solution on one side electrospun and AuNPs sprayed on the other side).

This was followed by characterizations through scanning electron microscopy (SEM), XRD, 
FTIR, tensile mechanical testing, electrical conductivity measurements, Raman spectroscopy, contact angle measurements and in vitro biocompatibility assays, and we will compare fabricated scaffolds using the two methods with bare CNFs. We will provide a thorough assessment of applicability of the prepared scaffolds for bone tissue engineering and electrical stimulation applications, and we will show, for the first time, that this structure is shown to be nontoxic and may be appropriate for bone tissue engineering applications.

\section{Experimental}

\subsection{Materials}

Polyacrylonitrile (PAN, MW=80000), Dimethylformamide (DMF), sodium citrate, and $\mathrm{HAuCl}_{4}$ were purchased from Merck (Germany). Fetal Bovine Serum (FBS), RPMI 1640 without phenol red and DMEM-high glucose media were all purchased from Gibco (USA). MTT Formazan was purchased from Sigma-Aldrich . Cytotoxicity Detection KitPLUS (LDH) was purchased from Roche. Human osteosarcoma cells, MG-63, were supplied by the National Cell Bank of Iran (NCBI), Pasteur Institute of Iran (NCBI, C555).

\subsection{Nanofibrous scaffold synthesis and carbonization}

\subsubsection{Preparation of carbon nanofibers}

To provide spinning polymer solution, we dissolved PAN powder in DMF solution at $60{ }^{\circ} \mathrm{C}$ under magnetic stirrer for 12 hours to prepare $9 \mathrm{wt} \%$ polymer solution of PAN. The electrospinning processes were carried out using an electrospinning equipment (Electroris, FNM, Tehran, Iran).

The electrospinning was carried out by applying a voltage of $20 \mathrm{kV}$ between the needle and the collector with rotation speed of $400 \mathrm{rpm}$ and rate of $1 \mathrm{~mm} / \mathrm{hr}$ at room temperature. Nanofiber plates electrospined with a thickness 100-120 $\mu \mathrm{m}$.

The electrospun mats was peeled from the aluminum foil and was treated with heat to stabilize and carbonize nanofibers to obtain carbon nanofibers. Stabilization and carbonization of PAN electrospun mats was done in a tube furnace (Azar,TF5/25-1720, Iran) according to our previous study. ${ }^{46}$ To prevent the PAN electrospun mats from shrinkage during the stabilization, 
PAN nanofibrous mats were cut into rectangular shape and pasted on graphite block by PAN solution. Stabilization was performed in air at $290{ }^{\circ} \mathrm{C}$ with heating rate of $1.5^{\circ} \mathrm{C} / \mathrm{min}$ and holding at $290{ }^{\circ} \mathrm{C}$ for $3 \mathrm{~h}$. The stabilized nanofibers were then taken apart from the graphite blocks and were carbonized at $1000^{\circ} \mathrm{C}$ under high purity nitrogen atmosphere (N2 99.9999\%, Air Products). The samples were heated at rate of $4{ }^{\circ} \mathrm{C} / \mathrm{min}$ and kept for $1 \mathrm{hr}$ at $1000{ }^{\circ} \mathrm{C}$.

\subsubsection{Gold nanoparticles/CNF blend electrospinning method (GCNF Blend)}

Three concentrations of gold nanoparticles were blended in 7\% PAN solution. The polymer concentration was reduced from $9 \% \mathrm{w} / \mathrm{v}$ to $7 \% \mathrm{w} / \mathrm{v}$ due to droplet formation during electrospinning for higher concentrations, which prevented effective electrospinning. 7\% PAN polymer solution was first prepared, since gold nanoparticles did not allow PAN polymerization DMF solution. The solution was then stirred at $60^{\circ} \mathrm{C}$ and $50 \mathrm{ppm}$ gold nanoparticle in water solution was later added with $1 \mathrm{w} / \mathrm{v} \%, 2.5 \mathrm{w} / \mathrm{v} \%$ and $5 \mathrm{w} / \mathrm{v} \%$. After stirring for $5 \mathrm{hr}$, the solution was electrospinned with $22 \mathrm{~V}$, at a $10 \mathrm{~cm}$ distance, with a rate of $1 \mathrm{~mm} / \mathrm{hr}$ to obtain gold nanoparticle-containing PAN nanofibers. Prior to this, gold nanoparticles were synthesized using a modified Turkevich method for gold nanoparticle synthesis to obtain 49 ppm gold nanoparticles with $25 \mathrm{~nm}$ size, which were then centrifuged at $10000 \mathrm{rpm}$ for $20 \mathrm{~min}$ to obtain higher concentrations. $^{53}$

\subsubsection{Gold Nanoparticles/CNF electrosprayed method (GCNF Sprayed)}

In the electrospraying method, polymer solution and gold nanoparticles were electrospun separately. Alternatively, 5\% and 10\% gold nanoparticles solutions (which were then centrifuged at $10000 \mathrm{rpm}$ for $20 \mathrm{~min}$ to obtain higher concentrations) were co-electrospinned with PAN nanofibers. This fabrication method relies on a side by side electrospinning systems, with one nozzle for nanofiber electrospinning, while the other nozzle is used for gold nanoparticle electrospraying. Stabilization is done similar to previous method, but the carbonization temperature is reduced by $800{ }^{\circ} \mathrm{C}$ under previous conditions.

\subsection{Scanning Electron Microscopy}

Scanning Electron Microscopy (SEM) (CM200-FEG-Philips) was used to characterize the micro- and nanostructure of the scaffolds. The mages were obtained using an acceleration voltage $25 \mathrm{kV}$ and a working distance of $13.6 \mathrm{~mm}$. Energy dispersive X-ray (EDX) was used to 
characterize dispersion of gold nanoparticles in the scaffold structure.

\subsection{Electrical conductivity measurement}

A simple four point apparatus was used for measuring the resistivity of semiconductor samples. Similar to previous work, ${ }^{54}$ passing a current through two outer probes and measuring the voltage through the inner probes allows the measurement of the substrate resistivity. Five samples were tested for each condition.

\subsection{Raman spectroscopy}

Raman spectroscopy was conducted to assess the crystallinity of the carbonized structures. This method has proved to be effective for characterizing carbon-based structures. D-band and G-band of the spectra represent graphitic carbon and structural disorder near the edge of crystalline structure, respectively, and the ratio of peak intensity is generally used for characterizing structural disorder. G-band appears near $1582 \mathrm{~cm}^{-1}$, while D-band is found around $1350 \mathrm{~cm}^{-1} .^{55-57}$ Raman spectrum of the samples were performed using Teksan Takram P50C0R10 raman spectrometer (laser wavelength: $532 \mathrm{~nm}$, laser power: 0.5-70 mW).

\subsection{Fourier-transform infrared spectroscopy (FTIR)}

The IR spectrum obtained from FTIR spectrometer lies in the mid-IR region between 4000 and $666 \mathrm{~cm}^{-1}$. Transition energies corresponding to changes in vibrational energy state for many functional groups are located in the mid-IR region and they can be indicative of appearance of an absorption band in this region can be used to determine whether specific functional groups exist within the structure. This characterization method was used to assess the structural changes in the samples due to the addition of gold nanoparticles. ${ }^{58}$

\subsection{X-ray diffraction}

A high resolution X-ray Diffractometer (PANalytical X'Pert Pro) with a $\mathrm{Cu} \mathrm{K} \alpha$ source $(\lambda=$ $0.1540598 \mathrm{~nm}$ ) was used to analyze the crystallinity of carbonized nanofibers and to investigate their microscopic structure. ${ }^{59}$

\subsection{Contact angle measurement}


Contact angle measurement was performed to assess the hydrophilicity of the surface. As described elsewhere, a contact angle of less than $90^{\circ}$ denotes a hydrophilic surface, while a surface with a contact angle of more than $90^{\circ}$ can be considered as a hydrophobic surface. ${ }^{60}$

\subsection{MTT assay}

Due to absorbance of MTT dye on carbonized nanofibers, indirect MTT assays were performed for the scaffolds. As described elsewhere, $1 \mathrm{ml}$ cell culture media without FBS per 0.1 gr scaffold was added to each sample and the incubated cell culture media was collected after 24, 48 and $72 \mathrm{hr}$ and supplemented with $10 \% \mathrm{FBS}$, and were subsequently added to wells containing MG-63 cells. Alternatively, for the direct cell culture on the scaffolds, they were sterilized with $70 \%$ ethanol and UV, and were placed and fixed on the bottom of a 48-well plate. Fixation using medical grade O-rings (C. Otto Gehrckens GmbH \& Co, Germany) was necessary to avoid any movement and to ensure proper cell seeding on top of the scaffolds. Cell seeding densities of 7000, 5000 and 3000 cell/cm2 was used for 24, 48 and $72 \mathrm{hr}$ experiments, respectively.

\subsection{LDH Cytotoxicity assay}

Lactate dehydrogenase (LDH) assay was first used to assess the cytotoxicity of our scaffolds. LDH Cytotoxicity kit (Roche Diagnostics, Germany) was used for this test according to the company protocol using negative and positive controls according to following formula:

$$
\text { Cytotoxicity }(\%)=\frac{\text { exp. value }- \text { low control }}{\text { high control }- \text { low control }} \times 100
$$

Similar to previous section, the scaffolds were rinsed with $\% 70$ ethanol and UV sterilized. MG-63 cells were cultured on the scaffolds seeding densities of 7000, 5000 and $3000 \mathrm{cell} / \mathrm{cm} 2$ was used for 24, 48 and $72 \mathrm{hr}$ experiments, respectively. RPMI media without phenol red and $1 \%$ FBS was used due to interference of phenol red and FBS with LDH adsorption.

\subsection{LDH proliferation assay}

Identical conditions were used for cell seeding on the scaffolds were placed in a $37{ }^{\circ} \mathrm{C}$ incubator with $90 \%$ humidity and $5 \% \mathrm{CO} 2$ for 24,48 and $72 \mathrm{hr}$. Cell culture media was 
extracted after the incubation periods and $100 \mu$ fresh DMEM media was added to each well. Lysing solution was added to each well and incubated for 15 min to ensure complete cell lysing. The entire cell culture media was transferred to other wells and mixed with LDH reaction mixture. Absorbance was measured at $290 \mathrm{~nm}$ after $10 \mathrm{~min}$ in room temperature. Proliferation was calculated using the following formula:

$$
\text { Proliferation }(\%)=\frac{\text { exp.value }}{\text { control.value }} \times 100
$$

\subsection{Cell attachment and morphology}

Scanning electron microscopy (SEM) was used to assess cell attachment and morphology on CNF and CNF/2.5\% AuNP scaffolds. Briefly, MG-63 cells were seeded on both types of scaffolds and they were fixed with $2 \mathrm{v} / \mathrm{v} \%$ glutaraldehyde. This was followed by consecutive steps of $20 \%, 40 \%, 60 \%, 80 \%$, and $96 \%$ ethanol treatment, each for $10 \mathrm{~min}$. The samples were sputter-coated with gold and SEM was used for visualization of cell attachment and morphology.

\subsection{Statistical analysis}

The experiments were performed with at least 5 repeats and the results were expressed as means with standard deviation. One-way analysis of variance (ANOVA) was used and $\mathrm{P}<0.05$ was used as the level of significance for statistical analysis.

\section{Results and discussion}

\subsection{Energy dispersive X-ray and Scanning Electron Microscopy}

EDX and SEM results of the scaffolds are shown in figure 1 and 2. EDX was performed to map the gold nanoparticles inside the scaffold structure and as it can be observed, contrary to what could have been a plausible issue, even after exposure to $800^{\circ} \mathrm{C}$ did not deteriorate the stability of gold nanoparticles inside the nanofibers and an almost homogenous distribution of gold nanoparticles is observed throughout the structure. Although cell morphology in SEM images is improved in the presence of $1 \%$ gold nanoparticles, the nanofibers are thick and are merges together due to the furnace heat. However, higher concentrations of gold nanoparticles 
contributed to separation of the fibers. As opposed to $5 \%$ concentration which exhibited more interfiber attachment and thicker fibers, sprayed samples and $2.5 \%$ concentration led to a reduction in nanofiber diameter, which can be attributed to gold nanoparticle surface charge.

As observed in figure 2, EDX results demonstrate a significant decrease of gold nanoparticle presence in electrosprayed form. This occurred despite the higher concentration of introduced gold nanoparticles. This can be attributed to the entrapment of gold nanoparticles in between the fibers in the mixture format as opposed to the loss in sprayed format. Electrosprayed scaffolds barely show any presence of gold nanoparticles and are almost indistinguishable from PAN fibers with no gold nanoparticles. Size-distribution of nanofibrous scaffolds has been presented in Table 1, which shows consistent fiber size distribution across all sample despite the addition of gold nanoparticles.

These results collectively show the effectiveness of our method for homogenous distribution of nanoparticles. As opposed to previous works which experience much difficulty in homogenous dispersion of gold nanoparticles, our simple and robust method prevented nanoparticle agglomeration. ${ }^{61-63}$ An alternative method in the letter based on adding gold nanoparticles after carbon nanofiber synthesis is also associated problems such as difficult integration of nanoparticles in the structure, which was avoided with our technique.

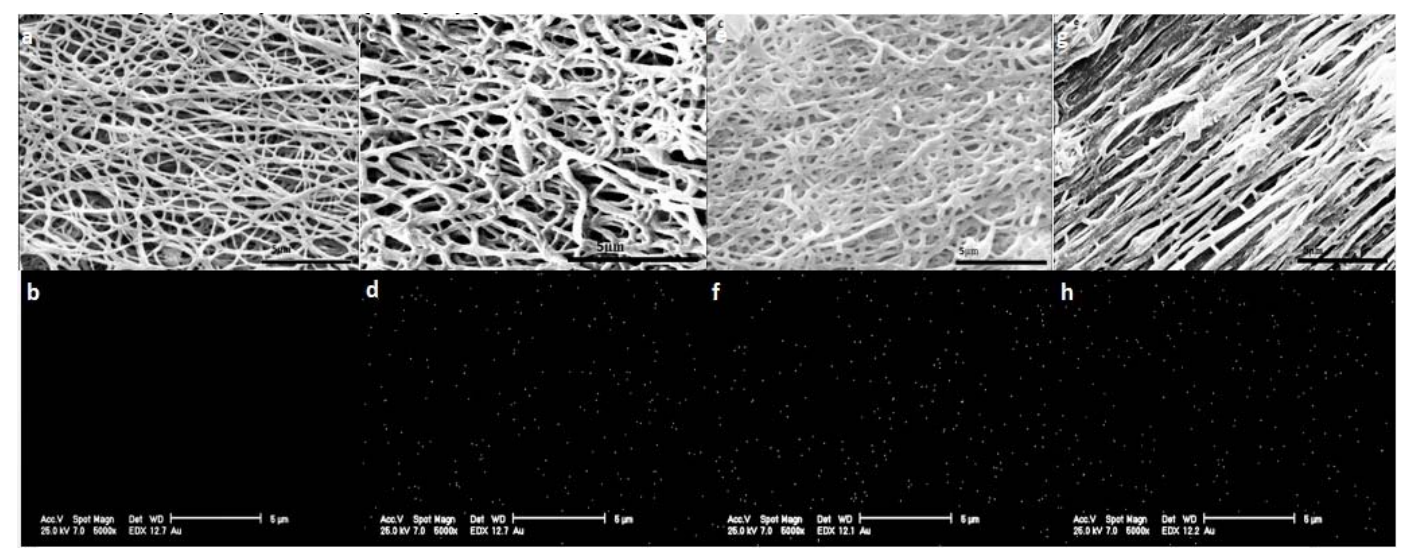

Figure 1. SEM and EDX characterization of the electrospinnned scaffolds. a) SEM of CNF, b) EDX of CNF (Au) c) SEM of CNF/1\% AuNP, d) EDX of CNF/1\% AuNP, e) SEM of CNF/2.5\% AuNP f) EDX of CNF/2.5\% AuNP(Au) $\mathrm{g}: \mathrm{SEM}$ of $\mathrm{CNF} / 5 \% \mathrm{AuNP}, \mathrm{h}) \mathrm{EDX}$ of $\mathrm{CNF} / 5 \% \mathrm{AuNP}(\mathrm{Au})$ 


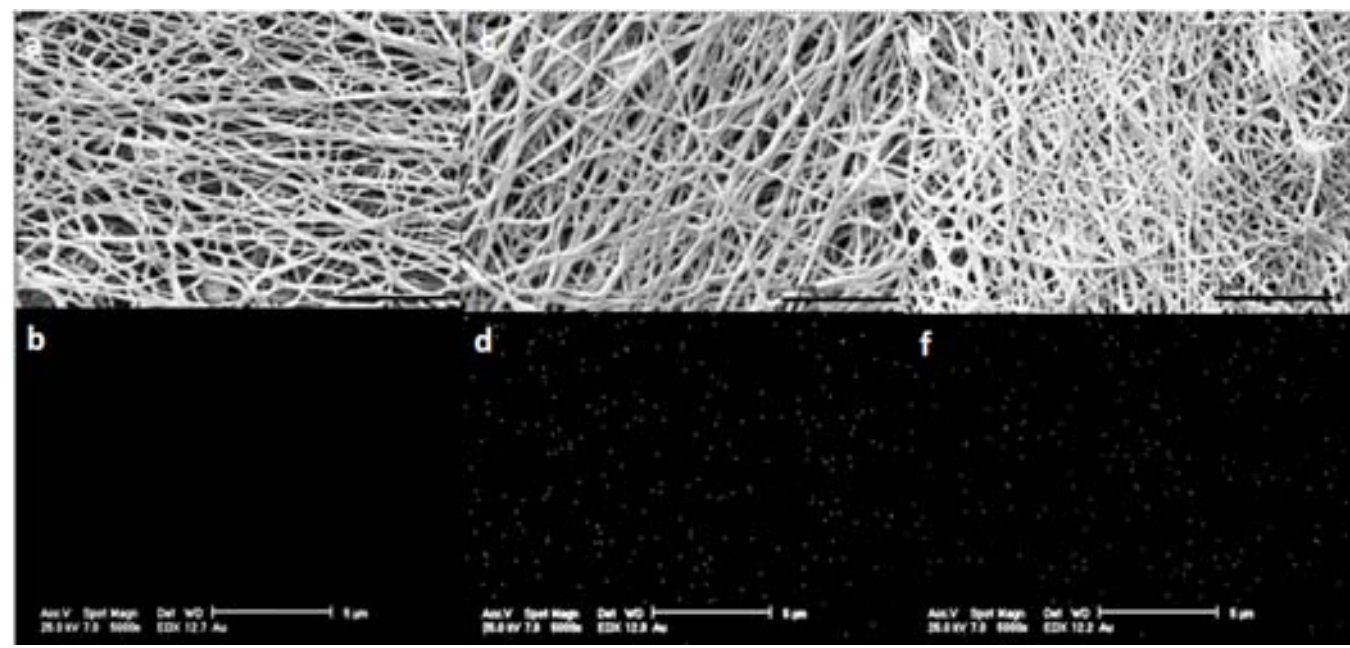

Figure 2. SEM and EDX characterization of the electrosprayed scaffolds. a) SEM of CNF, b) EDX of CNF(Au), c) SEM of CNF/5\% AuNP sprayed, d) EDX of CNF/5\% AuNP sprayed, e) SEM of CNF/10\% AuNP sprayed, f) EDX of $\mathrm{CNF} / 10 \%$ AuNP sprayed(Au).

Table 1. Nanofibrous scaffold fiber sizes under different conditions.

\begin{tabular}{|c|c|c|c|c|c|c|c|c|}
\hline \multirow{2}{*}{\multicolumn{2}{|c|}{$\begin{array}{c}\text { Sample } \\
\text { PAN }\end{array}$}} & \multirow{2}{*}{$\begin{array}{c}\text { Fiber size }(\mathbf{n m}) \\
152.90 \pm 24.51\end{array}$} & \multicolumn{2}{|c|}{ Sample } & Fiber size (nm) & \multicolumn{2}{|c|}{ Sample } & \multirow{2}{*}{$\begin{array}{r}\text { Fiber size }(\mathbf{n m}) \\
178.83 \pm 29.10\end{array}$} \\
\hline & & & \multirow{2}{*}{$\begin{array}{c}2.5 \% \\
\text { AuNP } \\
\text { Spinned }\end{array}$} & $\begin{array}{l}\text { Before } \\
\text { furnace }\end{array}$ & $122.54 \pm 29.23$ & & $\begin{array}{l}\text { Before } \\
\text { furnace }\end{array}$ & \\
\hline \multicolumn{2}{|c|}{$\mathrm{CNF}$} & $178.66 \pm 38.40$ & & $\begin{array}{c}\text { After } \\
\text { furnace }\end{array}$ & $157.94 \pm 24.14$ & Sprayed & $\begin{array}{c}\text { After } \\
\text { furnace }\end{array}$ & $120.81 \pm 13.77$ \\
\hline \multirow{2}{*}{$\begin{array}{c}1 \% \\
\text { AuNP } \\
\text { Spinned }\end{array}$} & $\begin{array}{l}\text { Before } \\
\text { furnace }\end{array}$ & $165.73 \pm 26.87$ & \multirow{2}{*}{$\begin{array}{c}5 \% \\
\text { AuNP } \\
\text { Spinned }\end{array}$} & $\begin{array}{l}\text { Before } \\
\text { furnace }\end{array}$ & $140.15 \pm 29.69$ & \multirow{2}{*}{$\begin{array}{c}10 \% \\
\text { AuNP } \\
\text { Sprayed }\end{array}$} & $\begin{array}{l}\text { Before } \\
\text { furnace }\end{array}$ & $177.16 \pm 27.93$ \\
\hline & $\begin{array}{l}\text { After } \\
\text { furnace }\end{array}$ & $182.56 \pm 52.22$ & & $\begin{array}{l}\text { After } \\
\text { furnace }\end{array}$ & $259.27 \pm 51.73$ & & $\begin{array}{l}\text { After } \\
\text { furnace }\end{array}$ & $157.8 \pm 24.58$ \\
\hline
\end{tabular}

\subsection{Electrical conductivity measurement}

The results of electrical conductivity measurements have been presented in Table 2 . There is a statistically significant increase in conductivity upon addition of $2.5 \%$ gold nanoparticles. However, addition of $5 \%$ gold nanoparticles led to a significant decrease in electrical conductivity, suggesting a possible disintegration in the nanofiber structure, leading to an adverse effect on conductivity. 
Table 2. Electrical properties of Carbonized Nanofibers under different conditions

\begin{tabular}{|c|c|c|c|c|c|c|}
\hline $\begin{array}{c}\text { Charachterisics of the } \\
\text { samples }\end{array}$ & $\mathbf{1 \% A u N P}$ & $\mathbf{2 . 5 \% \text { AuNP }}$ & $\mathbf{5 \% A u N P}$ & $\mathbf{5 \%}$ Sprayed & $\begin{array}{c}\mathbf{1 0 \%} \\
\text { Sprayed }\end{array}$ & CNF \\
\hline Conductivity $\left(\mathrm{s} . \mathrm{cm}^{-1}\right)$ & $3.15 \pm 0.32$ & $4.96 \pm 0.06$ & $2.65 \pm 0.06$ & $3.36 \pm 0.25$ & $3.54 \pm 0.18$ & $2.74 \pm 0.02$ \\
\hline Resistivity $(\Omega . \mathrm{cm})$ & $0.33 \pm 0.093$ & $0.25 \pm 0.056$ & $0.37 \pm 0.01$ & $0.29 \pm 0.031$ & $0.28 \pm 0.082$ & $0.36 \pm 0.027$ \\
\hline
\end{tabular}

\subsection{X-ray diffraction}

X-ray diffraction (XRD) analysis revealed amplified peaks at $2 \Theta=26^{\circ}$ and $2 \Theta=44^{\circ}$ corresponding to (001) and (002) planes, respectively (Figure 3). Additionally, the present weak peaks corresponding to gold nanoparticles confirmed their presence in the fibers for the mixture mode and on the surface for the sprayed mode. Peaks corresponding to gold nanoparticles were observed with different intensities in $2 \Theta=38^{\circ}, 2 \Theta=44^{\circ}, 2 \Theta=64^{\circ}$, and $2 \Theta=77^{\circ}$ for (111), (200), (220), and (311) planes, respectively (Table 3).

These results verified that using $800{ }^{\circ} \mathrm{C}$ furnace temperature didn't deteriorate the structural integrity of gold nanoparticles, which is consistent with previous reports of around $1000{ }^{\circ} \mathrm{C}$ melting temperature for nanoscale gold nanoparticles. ${ }^{61}$

XRD results confirmed the presence of graphite nanocrystals and shows a reduction in carbon nanofiber crystal size and elimination of graphite and amorphous domains. Smaller domains with graphite structure are also present in the samples. Wider peaks (especially in $2.5 \%$ samples) imply more crystalized structure. XRD analysis for scaffolds with mixture format showed the best performance in terms of graphite crystal. 


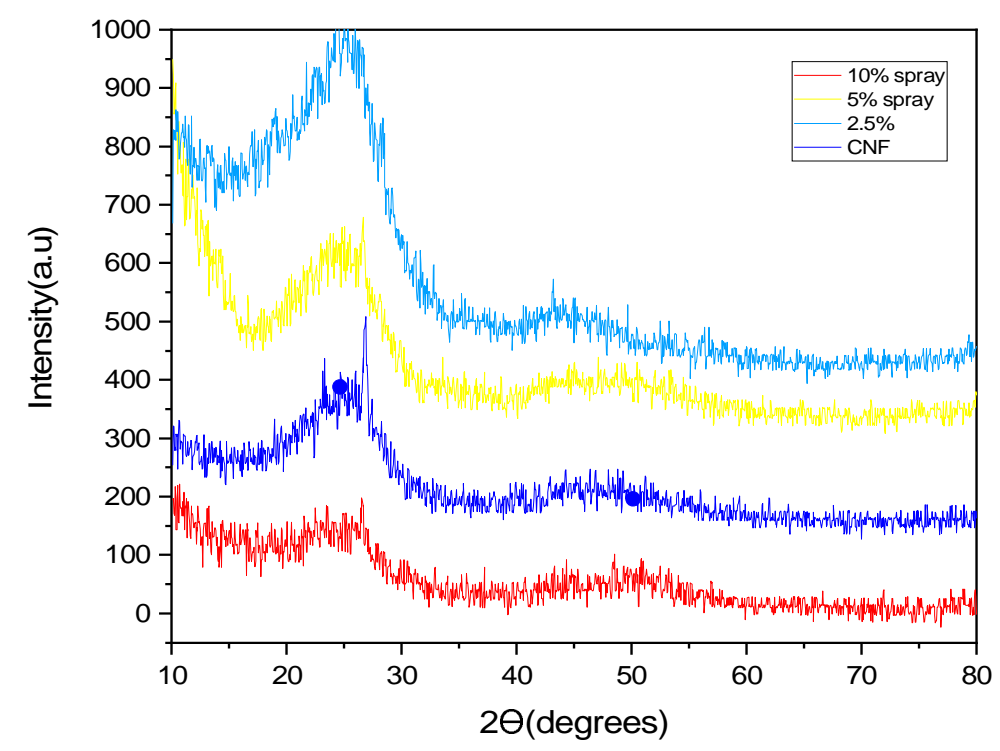

Figure 3. The X-ray diffraction (XRD) pattern of CNF and different combinations of CNF/AuNP

Additionally, XRD software analysis confirmed the presence of gold nanoparticles in $10 \%$ spray mode more distinctively more than the mixed mode samples. This can be attributed to the necessity of certain percentage to be detected by the tool ( $5 \%$ for mixed mode). One additional possibility for mixed mode samples is the presence of more gold nanoparticles in the inner layers of nanofibers. However, since the gold nanoparticles are on the surface and are in high concentration in the spray mode, they were easily detected by the XRD tool. The results showed the presence of gold nanoparticle crystals in cubic form with $a=4.06$ and $b=4.06$ and the carbon structures in hexagonal form with $\mathrm{a}=2.45, \mathrm{~b}=2.45$ and $\mathrm{c}=6.69$, collectively confirming the high thermal properties of gold nanoparticles in our scaffolds.

Table 3. XRD data of CNF and CNF/AuNP

\begin{tabular}{|c|c|c|c|c|}
\hline Samples & $\mathbf{2 \theta}$ & $\mathbf{B}$ (radian) & $\mathbf{D}(\mathbf{0 0 2}) \mathbf{( A}^{\circ}$ ) & $\mathbf{L c}(\mathbf{n m})$ \\
\hline CNF & 26.52 & 0.19 & 3.36 & 70 \\
\hline CNF/1\% AuNP(Blend) & 28.45 & 0.49 & 3.13 & 20 \\
\hline CNF/2.5\% AuNP(Blend) & 26.22 & 0.78 & 3.66 & 14 \\
\hline CNF/5\% AuNP (sprayed) & 26.65 & 0.29 & 3.34 & 46.66 \\
\hline CNF/10\% AuNP (sprayed) & 26.62 & 0.19 & 3.35 & 70 \\
\hline
\end{tabular}




\subsection{Raman spectroscopy}

Raman spectroscopy characterizations exhibited a decreased ID/IG ratio in samples with gold nanoparticles (Figure 4 and table 4). This was particularly evident in $2.5 \%$ gold nanoparticle samples, which confirmed the improved graphitization of carbon nanofibers as a result of gold nanoparticle addition. The gradual decrease in $\mathrm{G}$ values is a result of a decrease in graphite crystal size and elimination of amorphous carbon, which is consistent with XRD results. This can be attributed to surface plasmon resonance phenomenon of gold nanoparticles creating localized heat which has potentially contributed to an improvement in crystallinity and the graphite structure. $\mathrm{D} / \mathrm{G}$ ratio corresponds to edge to basal plane in graphite crystals and can be representative of graphite domains. ID $\neg / \mathrm{IG}$ ratios confirm an increase in graphite to edge ratio and a decrease in amorphous domains.

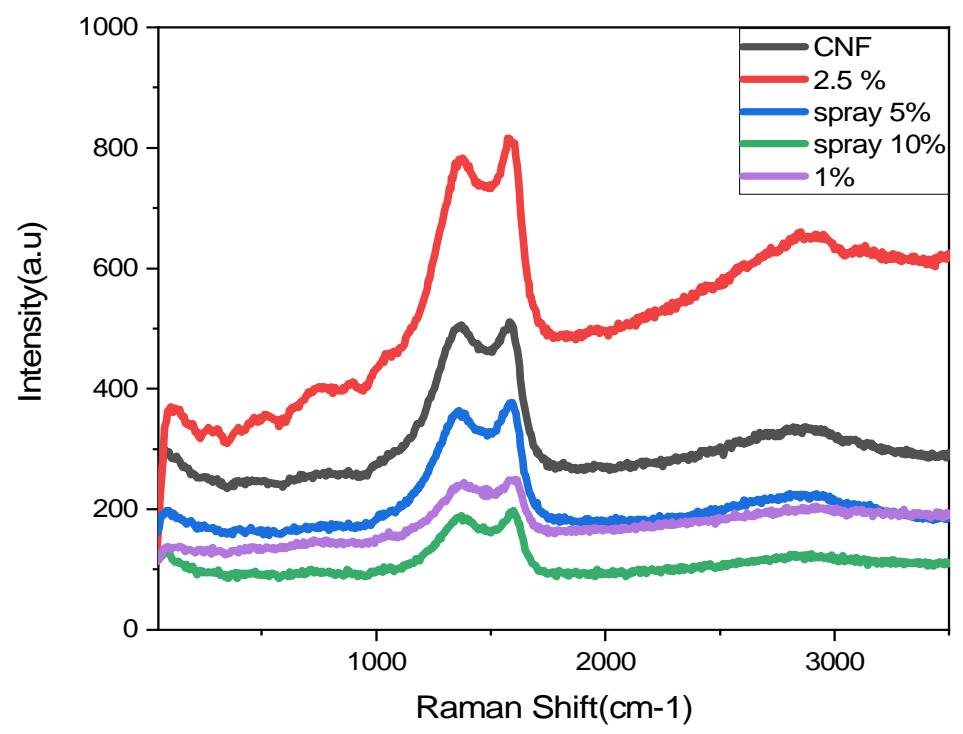

Figure 4. Raman Spectra of CNF and CNF/AuNP

Table 4. Peak Position and relative ratio of Raman peak intensities of CNF and CNF/AuNP

\begin{tabular}{|c|c|c|c|}
\hline Samples & $\begin{array}{c}\text { D position } \\
\left(\mathbf{c m}^{-1}\right)\end{array}$ & $\begin{array}{c}\mathbf{G}_{\text {position }} \\
\left(\mathbf{c m}^{-1}\right)\end{array}$ & $\mathbf{R}\left(\mathbf{I}_{\mathbf{D}} / \mathbf{I}_{\mathbf{G}}\right)$ \\
\hline $\mathrm{CNF}$ & 1372 & 1582 & $97 \%$ \\
\hline $\mathrm{CNF} / 1 \%$ AuNP(Blend) & 1376 & 1602 & $97 \%$ \\
\hline $\mathrm{CNF} / 2.5 \%$ AuNP(Blend) & 1376 & 1566 & $89 \%$ \\
\hline $\mathrm{CNF} / 5 \%$ AuNP(Blend) & 1355 & 1576 & $100 \%$ \\
\hline $\mathrm{CNF} / 5 \%$ AuNP (sprayed) & 1361 & 1552 & $92 \%$ \\
\hline $\begin{array}{c}\text { CNF/10\% AuNP } \\
\text { (sprayed) }\end{array}$ & 1372 & 1597 & $91 \%$ \\
\hline
\end{tabular}




\subsection{Fourier-transform infrared spectroscopy}

Fourier-transform infrared spectroscopy (FTIR) showed sharp peaks between 1800 and 1900 cm-1 wavelengths (Figure 5). These peaks are not present in fibers containing $2.5 \%$ gold nanoparticles, which confirms atomic level changes in carbon nanofiber surface due to the presence of gold nanoparticles.

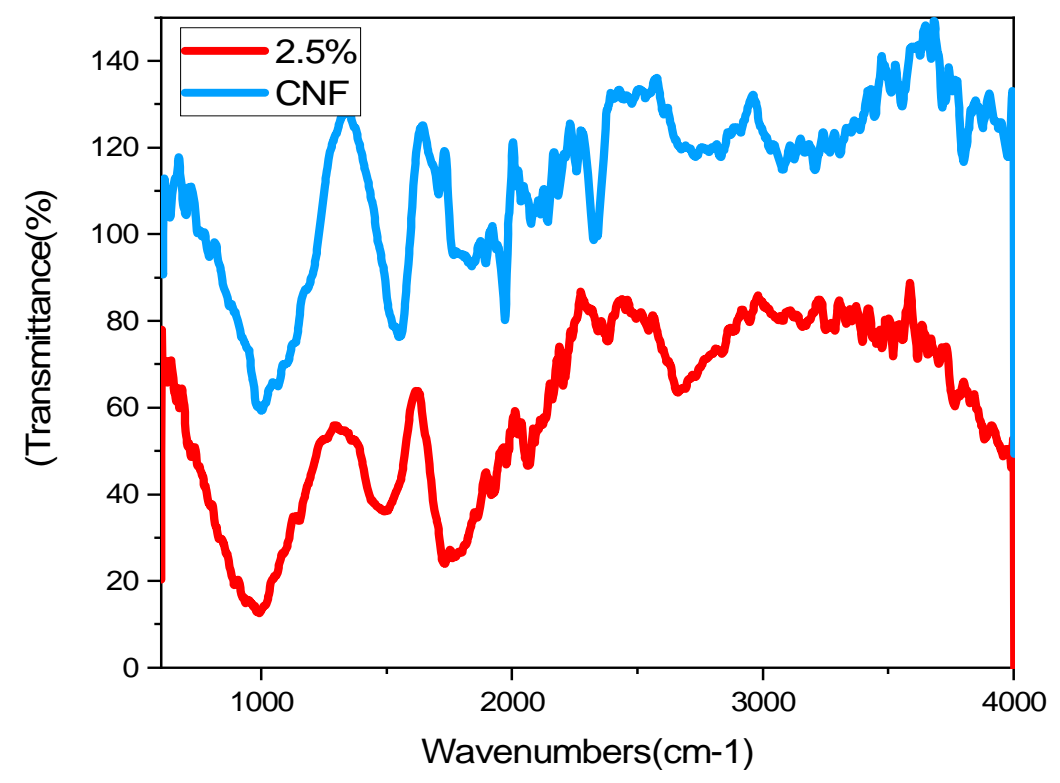

Figure 5. FT-IR Spectra of CNF and CNF/AuNP

\subsection{Contact angle measurement}

Contact angle measuements did not reveal any changes on the contact angle upon addition of gold nanoparticles and the surface hydrophilicity remained unchanged (Figure 6).

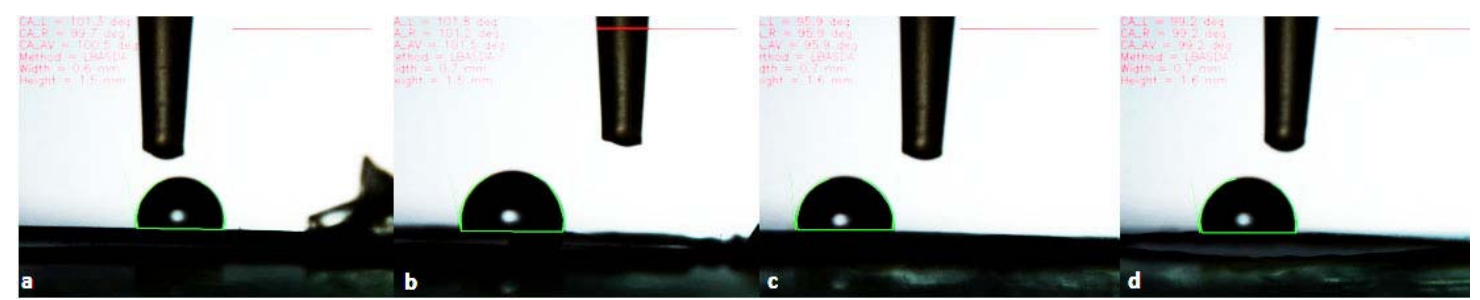

Figure 6. Contact angle measurement of nanofibrous scaffolds. a) CNF, b) PAN/CNF, c) CNF/ $2.5 \%$ AuNP, d) $\mathrm{CNF} / 5 \%$ sprayed AuNP. 


\subsection{MTT assay}

As stated before, indirect MTT assay was performed to assess the potential cytotoxicity of the prepared scaffolds. Although there was a slight decrease in cell viability in the prepared scaffolds and especially in the electrosprayed samples, this decrease was not statistically significant and therefore, the scaffolds all possessed biocompatibility (Figure 7). This argument is further solidified, considering that prolonged exposure (72 hours) shrunk this difference. Previous attempts on integration of gold nanoparticles in carbon-based structures were mostly focused towards application of such structures as electrodes, but here we demonstrate the efficacy of our design for biological application as evidenced by MTT, cytotoxicity and proliferation assays. ${ }^{64-66}$ These results are superior or at least similar as compared to previous works that have attempted to fabricate bone tissue scaffolds with similar compositions.

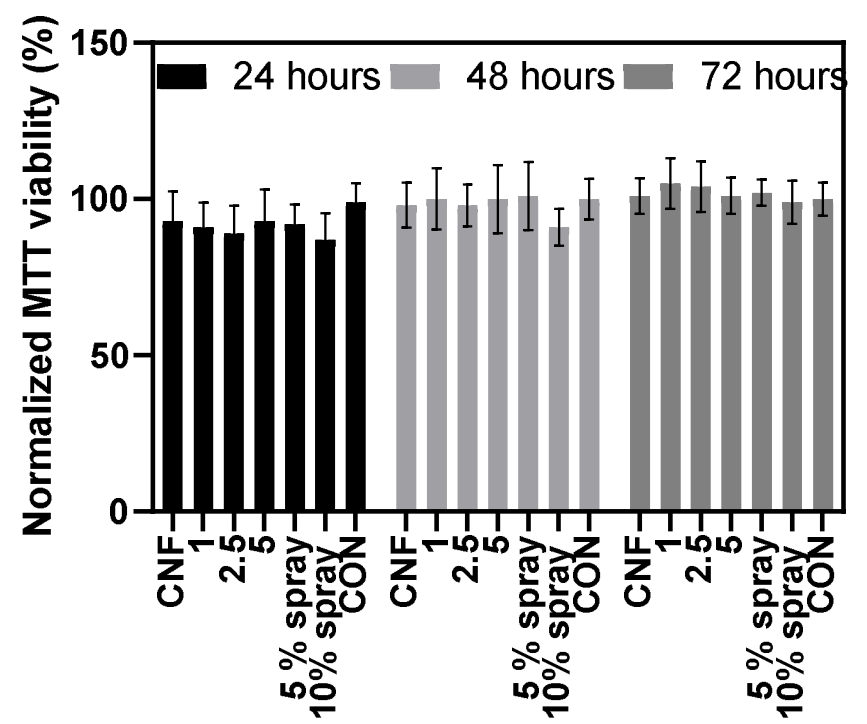

Figure 7. The indirect MTT assay result on the cell viability of Mg63 cells.

\subsection{LDH Cytotoxicity assay}

LDH cytotoxicity was utilized as an orthogonal method to assess scaffold biocompatibility. Although there was some perceived cytotoxicity over different time periods, still even in the worst case, cytotoxicity did not exceed $\% 10$, which is acceptable considering the components of the scaffolds and a simple comparison with previous reports further confirms potential superiority of our scaffold fabrication and modification as opposed to previously established methods (Figure 8). ${ }^{61,67,68}$ 


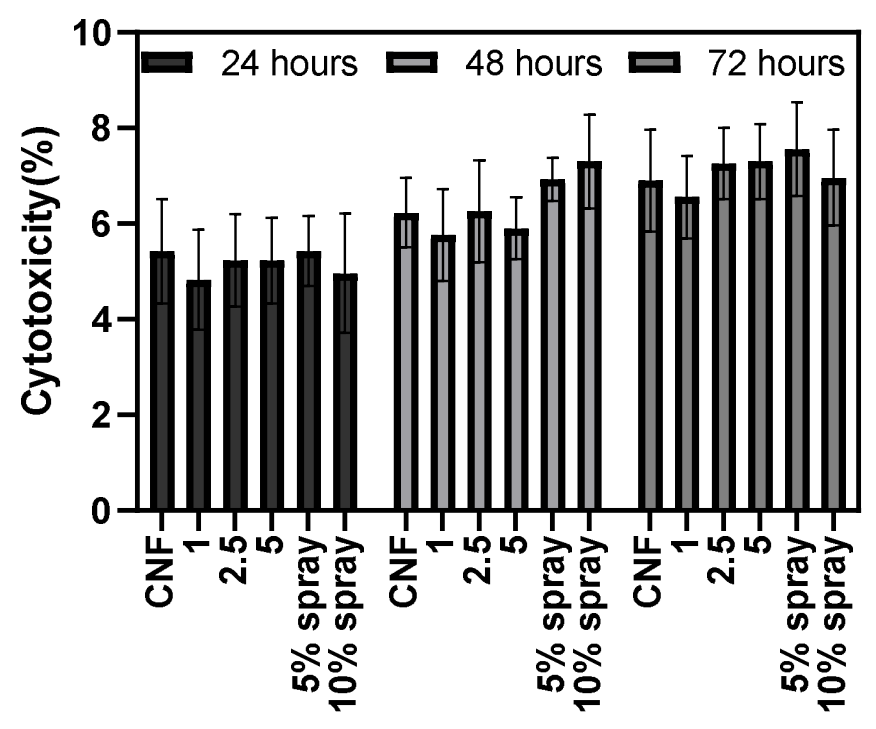

Figure 8. The LDH results of cytotoxicity on Mg63 Cells.

\subsection{LDH proliferation assay}

In addition to no significant cytotoxicity, any suitable scaffold should facilitate cell growth and proliferation as compared to golden standards such as tissue culture plastic controls (Figure 9). LDH proliferation assay showed significant proliferation on the scaffolds, comparable to tissue culture plastic controls. This suggests that cell seeding and subsequent proliferation on the prepared scaffolds can potentially be used to create cell-laden scaffolds for in vitro or in vivo assays which could pave the way for clinical applications of the prepared scaffolds. 


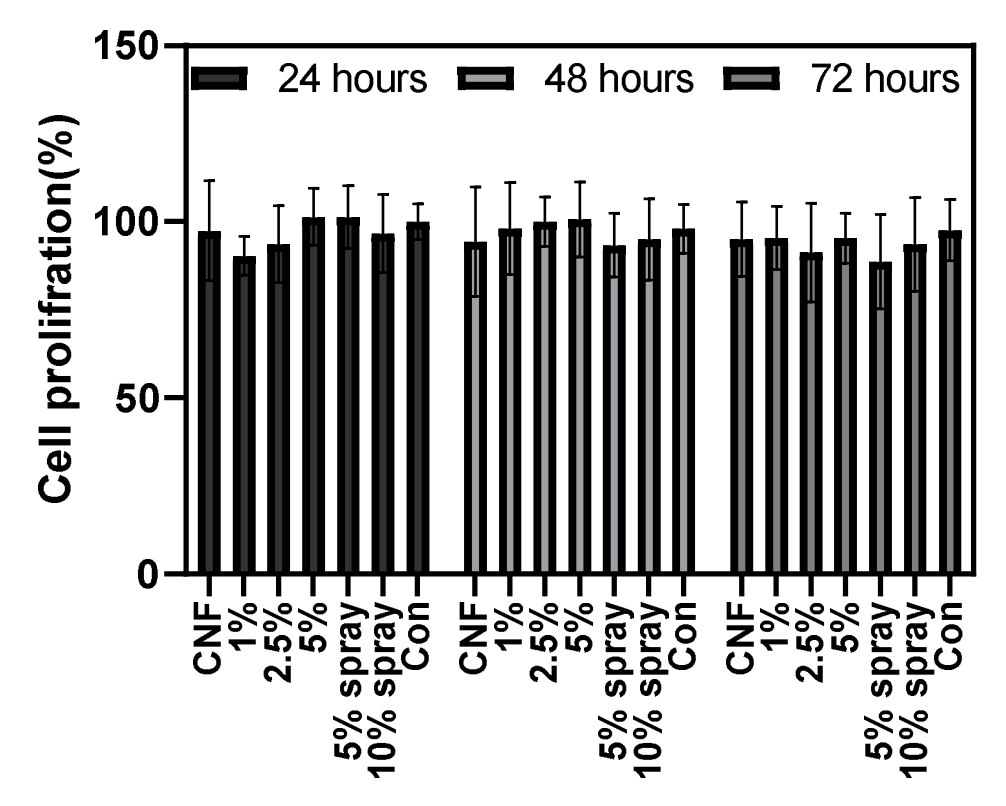

Figure 9. Cell Proliferation of Mg-63 Cells on CNF and CNF/AuNP

\subsection{Cell attachment and morphology}

As discussed previously, cell culture, fixation and scanning electron microscopy (SEM) was performed for a preliminary assessment of cell attachment and morphology. As it can be observed from Figure 10, SEM showed proper cell attachment and cell spreading both on carbon nanofibrous scaffolds with and without the presence of gold nanoparticles. Normal morphology and attachment of MG-63 cells can be interpreted as promising with future continual of this work for further in vitro and in vivo studies as the use of similar structures in the literature has entailed controversy regarding their potential cytotoxicity. Considering these results and previous data shown in this work on direct and indirect cell cytotoxicity, we have obtained a method with minimal cytotoxicity as opposed to similar works in the literature. 


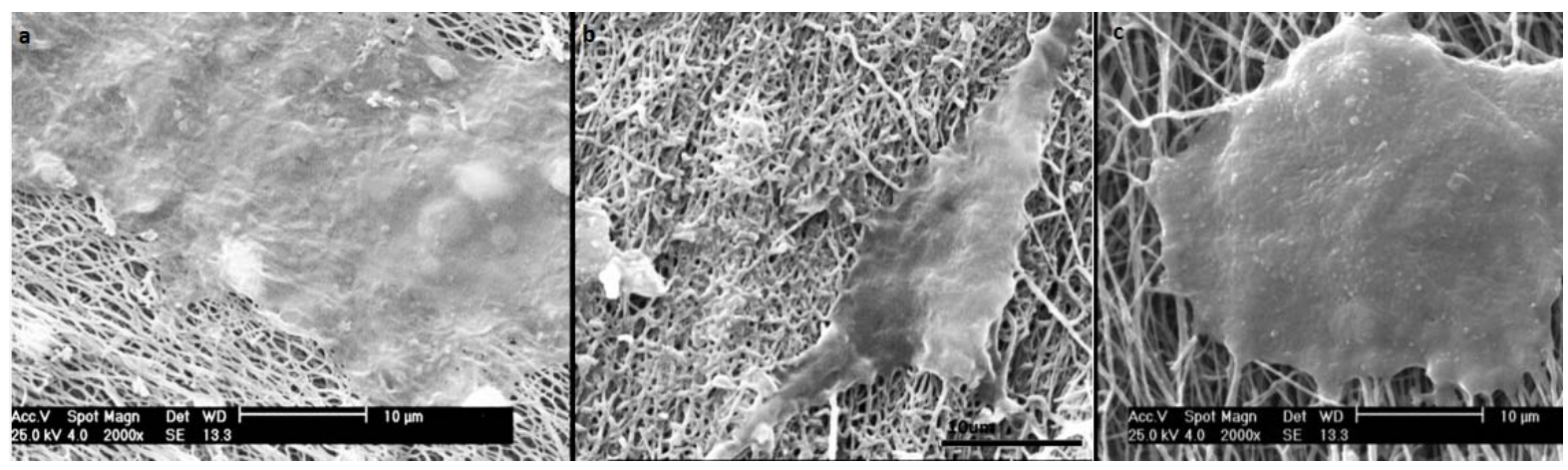

Figure 10. Cell attachment and morphology on CNF (a) and CNF/2.5\% AUNP scaffolds (b) $5 \%$ GNP

Sprayed on CNF(c)

\section{Conclusions}

In this work, through simple and highly controllable fabrication methods and by relying on incorporation of gold nanoparticles in a carbon nanofiber matrix, not only we improved the electrical and physical properties of the scaffolds, we were also able to maintain and significantly improve the biological response and cell-substrate interactions of our scaffolds.

We observed that gold nanoparticles can be embedded in carbon nanofibers structures using two distinct methods (GCNF blended and GCNF sprayed). The effects of gold nanoparticles on the carbon nanofibers structure were investigated through comprehensive characterizations. The addition of nanoparticles in both methods resulted in a decrease nanofibers sizes but was more effective in the electro-spraying format, in which uniform size distribution and a better morphology with less adhesion between nanofibers was observed. This may be attributed to electrostatic repulsion induced by gold nanoparticles on the surface of nanofibers. The XRD results demonstrated that improvement was observed in carbon nanofibers crystals in the presence of gold nanoparticles. On the other hand, the crystalline form of the gold nanoparticles was shown to indicate that the furnace process had no effect on the structure of the gold nanoparticles. Raman spectroscopy results showed graphitic structure enhancement that probably was caused due to local heat induced by the plasmon surface of the nanoparticles and this could explain the improvement in the electrical conductivity of the structure. The FT-IR results also showed changes in the surface chemistry of the nanofibers, but the changes were not sufficient to result in changes in the surface hydrophilicity, considering contact angle results 
show no significant difference between samples containing gold nanoparticles and carbon nanofibers. Toxicity tests indirect MTT and LDH showed that the carbon nanofibers and nanofibers containing gold nanoparticles (GCNF blended and GCNF sprayed) did not induce any cytotoxicity and was biocompatible with the MG-63 cells, while the results of cell proliferation showed no difference between the control and carbon nanofibers and GCNF blended and sprayed.

Such scaffold fabrication strategy can be further explored in future studies in combination with exogenous in vitro electrical stimulation, with potential expansion to in vivo studies and eventually reaching clinical work. However, such translation requires further biological and biophysical characterization and more in-depth research into the underlying mechanisms for any improvement in regeneration as a result of electrical conductivity and electrical stimulation. We believe that the presented results provide suitable platforms for such endeavors in our research group and also, in the tissue engineering community.

Most of previous applications for scaffolds with similar formulations in the literature were for detection and sensor applications and did not thoroughly assess cytotoxicity or proliferation, in contrast with our current study which thoroughly addressed cytotoxicity and proliferation for bone cells. ${ }^{64-66}$ Our results have potentials and implications for future work on osteogenic differentiation and assessing the in vitro and in vivo effects of electrical conductivity and exogenous electrical signaling, stemming partly from successful embedment of gold nanoparticles.

\section{Funding:}

This work was supported by Tehran University of Medical Sciences, grant no. 98-01-8741015.

\section{Conflict of Interest}

The authors declare no conflict of interest.

\section{References}

1. Porter, J. R., Ruckh, T. T. \& Popat, K. C. Bone tissue engineering: a review in bone 
biomimetics and drug delivery strategies. Biotechnol. Prog. 25, 1539-1560 (2009).

2. Roseti, L. et al. Scaffolds for bone tissue engineering: state of the art and new perspectives. Mater. Sci. Eng. C 78, 1246-1262 (2017).

3. Nair, B. P., Sindhu, M. \& Nair, P. D. Polycaprolactone-laponite composite scaffold releasing strontium ranelate for bone tissue engineering applications. Colloids Surfaces $B$ Biointerfaces 143, 423-430 (2016).

4. Abbasian, M., Massoumi, B., Mohammad-Rezaei, R., Samadian, H. \& Jaymand, M. Scaffolding polymeric biomaterials: Are naturally occurring biological macromolecules more appropriate for tissue engineering? Int. J. Biol. Macromol. (2019).

5. Turk, M. \& Deliormanl, A. M. Electrically conductive borate-based bioactive glass scaffolds for bone tissue engineering applications. J. Biomater. Appl. 32, 28-39 (2017).

6. Kim, M., Yun, H. \& Kim, G. H. Electric-field assisted 3D-fibrous bioceramic-based scaffolds for bone tissue regeneration: Fabrication, characterization, and in vitro cellular activities. Sci. Rep. 7, 1-13 (2017).

7. Samadian, H. et al. Electro-conductive carbon nanofibers as the promising interfacial biomaterials for bone tissue engineering. J. Mol. Liq. 112021 (2019).

8. Türk, S. et al. 3D porous collagen/functionalized multiwalled carbon nanotube/chitosan/hydroxyapatite composite scaffolds for bone tissue engineering. Mater. Sci. Eng. C 92, 757-768 (2018).

9. Wasupalli, G. K. \& Verma, D. Injectable and thermosensitive nanofibrous hydrogel for bone tissue engineering. Mater. Sci. Eng. C 107, 110343 (2020).

10. Gholizadeh, S. et al. Preparation and characterization of novel functionalized multiwalled carbon nanotubes/chitosan/ $\beta$-Glycerophosphate scaffolds for bone tissue engineering. Int. J. Biol. Macromol. (2017) doi:10.1016/j.ijbiomac.2016.12.086.

11. Allahyari, Z. et al. Optimization of electrical stimulation parameters for MG-63 cell proliferation on chitosan/functionalized multiwalled carbon nanotube films. $R S C A d v \mathbf{6}$, 109902-109915 (2016).

12. Samadian, H. et al. Effective parameters on conductivity of mineralized carbon nanofibers: an investigation using artificial neural networks. RSC Adv. 6, 111908-111918 (2016).

13. Winkler, T., Sass, F. A., Duda, G. N. \& Schmidt-Bleek, K. A review of biomaterials in bone defect healing, remaining shortcomings and future opportunities for bone tissue engineering: The unsolved challenge. Bone Joint Res. 7, 232-243 (2018).

14. Leppik, L. et al. Combining electrical stimulation and tissue engineering to treat large bone defects in a rat model. Sci. Rep. 8, 1-14 (2018).

15. Kozhevnikov, E. et al. Electrical impedance spectroscopy-a potential method for the study and monitoring of a bone critical-size defect healing process treated with bone tissue 
engineering and regenerative medicine approaches. J. Mater. Chem. B 4, 2757-2767 (2016).

16. Samadian, H., Mobasheri, H., Hasanpour, S. \& Faridi-Majid, R. Needleless electrospinning system, an efficient platform to fabricate carbon nanofibers. in Journal of Nano Research vol. 50 78-89 (Trans Tech Publ, 2017).

17. Khoshnevisan, K. et al. Cellulose acetate electrospun nanofibers for drug delivery systems: Applications and recent advances. Carbohydr. Polym. 198, 131-141 (2018).

18. Massoumi, B. et al. A novel bio-inspired conductive, biocompatible, and adhesive terpolymer based on polyaniline, polydopamine, and polylactide as scaffolding biomaterial for tissue engineering application. Int. J. Biol. Macromol. 147, 1174-1184 (2020).

19. Farzamfar, S. et al. Neural tissue regeneration by a gabapentin-loaded cellulose acetate/gelatin wet-electrospun scaffold. Cellulose 25, 1229-1238 (2018).

20. Samadian, H. et al. In vitro and in vivo evaluation of electrospun cellulose acetate/gelatin/hydroxyapatite nanocomposite mats for wound dressing applications. Artif. cells, nanomedicine, Biotechnol. 46, 964-974 (2018).

21. Samadian, H. et al. Naturally occurring biological macromolecules-based hydrogels: Potential biomaterials for peripheral nerve regeneration. Int. J. Biol. Macromol. (2020).

22. Sepahvandi, A., Eskandari, M. \& Moztarzadeh, F. Fabrication and characterization of SrAl2O4: Eu2+ Dy3+/CS-PCL electrospun nanocomposite scaffold for retinal tissue regeneration. Mater. Sci. Eng. C 66, 306-314 (2016).

23. Yoshimoto, H., Shin, Y. M., Terai, H. \& Vacanti, J. P. A biodegradable nanofiber scaffold by electrospinning and its potential for bone tissue engineering. Biomaterials 24, 2077-2082 (2003).

24. Sharifi, E. et al. Preparation of a biomimetic composite scaffold from gelatin/collagen and bioactive glass fibers for bone tissue engineering. Mater. Sci. Eng. C 59, 533-541 (2016).

25. Č́íková, E. et al. Conducting electrospun polycaprolactone/polypyrrole fibers. Synth. Met. 235, 80-88 (2018).

26. Jaymand, M. et al. Development of novel electrically conductive scaffold based on hyperbranched polyester and polythiophene for tissue engineering applications. J. Biomed. Mater. Res. Part A 104, 2673-2684 (2016).

27. Massoumi, B. \& Jaymand, M. Chemical and electrochemical grafting of polythiophene onto poly (methyl methacrylate), and its electrospun nanofibers with gelatin. J. Mater. Sci. Mater. Electron. 27, 12803-12812 (2016).

28. Bertuoli, P. T. et al. Electrospun conducting and biocompatible uniaxial and Core-Shell fibers having poly (lactic acid), poly (ethylene glycol), and polyaniline for cardiac tissue engineering. ACS omega 4, 3660-3672 (2019).

29. Guo, B. \& Ma, P. X. Conducting polymers for tissue engineering. Biomacromolecules 19, 
1764-1782 (2018).

30. Shafei, S. et al. Electroactive nanostructured scaffold produced by controlled deposition of PPy on electrospun PCL fibres. Res. Chem. Intermed. 43, 1235-1251 (2017).

31. Baptista, A. C. et al. Cellulose-based electrospun fibers functionalized with polypyrrole and polyaniline for fully organic batteries. J. Mater. Chem. A 6, 256-265 (2018).

32. Ribeiro, S., Correia, D. M., Ribeiro, C. \& Lanceros-Méndez, S. Electrospun polymeric smart materials for tissue engineering applications. in Electrospun biomaterials and related technologies 251-282 (Springer, 2017).

33. Ghasemi $\square$ Mobarakeh, L. et al. Application of conductive polymers, scaffolds and electrical stimulation for nerve tissue engineering. J. Tissue Eng. Regen. Med. 5, e17-e35 (2011).

34. Pillai, M. M., Kumar, G. S., Houshyar, S., Padhye, R. \& Bhattacharyya, A. Effect of nanocomposite coating and biomolecule functionalization on silk fibroin based conducting $3 \mathrm{D}$ braided scaffolds for peripheral nerve tissue engineering. Nanomedicine Nanotechnology, Biol. Med. 24, 102131 (2020).

35. Chen, H. et al. Tailoring surface nanoroughness of electrospun scaffolds for skeletal tissue engineering. Acta Biomater. 59, 82-93 (2017).

36. Shalumon, K. T. et al. Single step electrospinning of chitosan/poly (caprolactone) nanofibers using formic acid/acetone solvent mixture. Carbohydr. Polym. 80, 413-419 (2010).

37. Martins, A. M. et al. Electrically conductive chitosan/carbon scaffolds for cardiac tissue engineering. Biomacromolecules 15, 635-643 (2014).

38. Rajzer, I., Kwiatkowski, R., Piekarczyk, W., Biniaś, W. \& Janicki, J. Carbon nanofibers produced from modified electrospun PAN/hydroxyapatite precursors as scaffolds for bone tissue engineering. Mater. Sci. Eng. C 32, 2562-2569 (2012).

39. Deng, L., Young, R. J., Kinloch, I. A., Zhu, Y. \& Eichhorn, S. J. Carbon nanofibres produced from electrospun cellulose nanofibres. Carbon N. Y. 58, 66-75 (2013).

40. Samadian, H. et al. Electrospun cellulose acetate/gelatin nanofibrous wound dressing containing berberine for diabetic foot ulcer healing: in vitro and in vivo studies. bioRxiv 787093 (2019).

41. Arshad, S. N., Naraghi, M. \& Chasiotis, I. Strong carbon nanofibers from electrospun polyacrylonitrile. Carbon N. Y. 49, 1710-1719 (2011).

42. Sharma, Y. et al. Fabrication of conducting electrospun nanofibers scaffold for threedimensional cells culture. Int. J. Biol. Macromol. 51, 627-631 (2012).

43. Ghasemi-Mobarakeh, L., Prabhakaran, M. P., Morshed, M., Nasr-Esfahani, M. H. \& Ramakrishna, S. Electrical stimulation of nerve cells using conductive nanofibrous scaffolds for nerve tissue engineering. Tissue Eng. Part A 15, 3605-3619 (2009). 
44. Liang, H. et al. Accelerated Bone Regeneration by Gold-Nanoparticle-Loaded Mesoporous Silica through Stimulating Immunomodulation. ACS Appl. Mater. Interfaces 11, 4175841769 (2019).

45. Zhang, D., Liu, D., Zhang, J., Fong, C. \& Yang, M. Gold nanoparticles stimulate differentiation and mineralization of primary osteoblasts through the ERK/MAPK signaling pathway. Mater. Sci. Eng. C 42, 70-77 (2014).

46. Mirzaei, E. et al. Functionalization of PAN-based electrospun carbon nanofibers by acid oxidation: study of structural, electrical and mechanical properties. Fullerenes, Nanotub. Carbon Nanostructures 23, 930-937 (2015).

47. Bajaj, P., Khang, D. \& Webster, T. J. Control of spatial cell attachment on carbon nanofiber patterns on polycarbonate urethane. Int. J. Nanomedicine 1, 361 (2006).

48. Zhang, T. et al. Biotemplated synthesis of gold nanoparticle-bacteria cellulose nanofiber nanocomposites and their application in biosensing. Adv. Funct. Mater. 20, 1152-1160 (2010).

49. Mallick, K., Witcomb, M. J., Dinsmore, A. \& Scurrell, M. S. Fabrication of a metal nanoparticles and polymer nanofibers composite material by an in situ chemical synthetic route. Langmuir 21, 7964-7967 (2005).

50. Samadian, H. et al. Genotoxicity assessment of carbon-based nanomaterials; Have their unique physicochemical properties made them double-edged swords? Mutat. Res. Mutat. Res. 108296 (2020).

51. de Castro, J. G. et al. Designing a novel nanocomposite for bone tissue engineering using electrospun conductive PBAT/polypyrrole as a scaffold to direct nanohydroxyapatite electrodeposition. RSC Adv. 6, 32615-32623 (2016).

52. Shao, H. et al. 3D gel-printing of hydroxyapatite scaffold for bone tissue engineering. Ceram. Int. 45, 1163-1170 (2019).

53. Kimling, J. et al. Turkevich method for gold nanoparticle synthesis revisited. J. Phys. Chem. $B$ 110, 15700-15707 (2006).

54. Schroder, D. K. Semiconductor material and device characterization. (John Wiley \& Sons, 2015).

55. Ferrari, A. C. et al. Raman spectrum of graphene and graphene layers. Phys. Rev. Lett. 97, 187401 (2006).

56. Pimenta, M. A. et al. Studying disorder in graphite-based systems by Raman spectroscopy. Phys. Chem. Chem. Phys. 9, 1276-1290 (2007).

57. Muzyka, R., Drewniak, S., Pustelny, T., Chrubasik, M. \& Gryglewicz, G. Characterization of graphite oxide and reduced graphene oxide obtained from different graphite precursors and oxidized by different methods using Raman spectroscopy. Materials (Basel). 11, 1050 (2018). 
58. Mohamed, M. A., Jaafar, J., Ismail, A. F., Othman, M. H. D. \& Rahman, M. A. Fourier transform infrared (FTIR) spectroscopy. in Membrane Characterization 3-29 (Elsevier, 2017).

59. Gotthard, G., Hiblot, J., Elias, M. \& Chabrière, E. Crystallization and preliminary X-ray diffraction analysis of the hyperthermophilic Sulfolobus islandicus lactonase. Acta Crystallogr. Sect. F Struct. Biol. Cryst. Commun. 67, 354-357 (2011).

60. Gittens, R. A. et al. A review on the wettability of dental implant surfaces II: Biological and clinical aspects. Acta Biomater. 10, 2907-2918 (2014).

61. McKeon $\square$ Fischer, K. D. \& Freeman, J. W. Characterization of electrospun poly (L $\square$ lactide) and gold nanoparticle composite scaffolds for skeletal muscle tissue engineering. J. Tissue Eng. Regen. Med. 5, 560-568 (2011).

62. Baranes, K., Shevach, M., Shefi, O. \& Dvir, T. Gold nanoparticle-decorated scaffolds promote neuronal differentiation and maturation. Nano Lett. 16, 2916-2920 (2016).

63. Sridhar, R., Sundarrajan, S., Venugopal, J. R., Ravichandran, R. \& Ramakrishna, S. Electrospun inorganic and polymer composite nanofibers for biomedical applications. $J$. Biomater. Sci. Polym. Ed. 24, 365-385 (2013).

64. Niu, X. et al. A novel electrochemical sensor of bisphenol A based on stacked graphene nanofibers/gold nanoparticles composite modified glassy carbon electrode. Electrochim. Acta 98, 167-175 (2013).

65. Xu, S. et al. Self-assembled polymeric nanoparticles film stabilizing gold nanoparticles as a versatile platform for ultrasensitive detection of carcino-embryonic antigen. Biosens. Bioelectron. 92, 570-576 (2017).

66. Sabury, S., Kazemi, S. H. \& Sharif, F. Graphene-gold nanoparticle composite: application as a good scaffold for construction of glucose oxidase biosensor. Mater. Sci. Eng. C 49, 297-304 (2015).

67. Yang, X. et al. Pharmaceutical intermediate-modified gold nanoparticles: against multidrugresistant bacteria and wound-healing application via an electrospun scaffold. ACS Nano 11, 5737-5745 (2017).

68. Sridhar, S., Venugopal, J. R., Sridhar, R. \& Ramakrishna, S. Cardiogenic differentiation of mesenchymal stem cells with gold nanoparticle loaded functionalized nanofibers. Colloids Surfaces B Biointerfaces 134, 346-354 (2015). 